\title{
Numerical modeling techniques for the evaluation of the dynamic effects induced by excavation in existing structures
}

\author{
M. Sangirardi, F. Porco, G. Uva \& A. Fiore \\ DICATECh, Politecnico di Bari, Italy
}

\begin{abstract}
The dynamic behaviour of an existing building is sometimes difficult to predict, particularly when the information available for the specific case study is not as much as would be necessary for a complete description of the structure.

Dynamic response to vibration induced by external natural/artificial sources, thanks to the relative ease with which it can be measured and analysed, makes vibration-based assessment an attractive complement to traditional visual inspection and nondestructive evaluation methods. This study moves from an investigation that is being carried out on a building sited in the port area of Bari, Apulia, where excavation and dredging operations are thought to be responsible for a series of damage that could involve structural and non structural elements in the monitored buildings due to vibration induced in the entire surrounding area. Having the chance to measure the real acceleration and displacement at the basement floor and in some other relevant parts of the building, it will be possible to update the finite element model, matching the response of the FE model in a series of combinations of parameters with the real measured dynamic excitation. Many other studies regarding dynamic identification and the usual modern methods make use of ambient-vibration induced by the so-called environmental noise or, otherwise, inducing a dynamic response by artificial sources of vibration. In this research work the source is known in terms of frequency and magnitude and, so, with an adaptive procedure it will be possible to predict the future damage, serviceability loss or, more generally, the performance of the building towards different combinations of static and dynamic loads.
\end{abstract}

Keywords: modal analysis, excavation, vibration, monitoring, numerical modelling. 


\section{Introduction}

With advances in high-speed data acquisition technology and dynamic system identification techniques, vibration-based assessment has emerged as a viable option for monitoring civil infrastructures. Information embedded in vibration signatures reflects a wide variety of structural characteristics, making it possible to evaluate many different aspects of the structural condition with relatively few sensors. The global nature of the dynamic response, coupled with the relative ease with which it can be measured and analysed, makes vibration-based assessment an attractive complement to traditional visual inspection and nondestructive evaluation methods.

The study presented is being carried out in order to evaluate the seismic behaviour of an existing r.c. building located in the port area of Bari (Italy) and to predict its performance against different combinations of static and dynamic loads, induced vibrations.

Dynamic identification and experimental modal analysis techniques are currently wide-spreading themes in the civil engineering field, since detecting actual structural response due to various external loadings, impacts, wind actions, environmental noise, can provide a series of important information on the operating state and the structural safety of the investigated structures.

Various methods for structural identification have been developed and this topic has attracted the interest of many researchers.

The procedures developed for the classical experimental modal analysis typically require the structure to be installed in a laboratory under conditions where simultaneous measurement of both the response and loadings in some relevant points of the considered structure are possible [1].

The aim of most of the studies in this field is to investigate how dynamic characteristics can be used to detect and evaluate damage in concrete structures. In these structures, damage is associated with structural modifications, which can be observed through changes in modal parameters: resonant frequencies, modal damping ratios, mode shapes and their derivatives [2].

Modal testing techniques are used to determine these modal parameters, by performing curve fitting procedures either on series of measured frequency response functions (FRFs), or on time histories of the structures dynamic response. Several researchers have already investigated changes in dynamic characteristics with simulated damage, using both model and real structures $[3,4]$. A literature review can be found in [5].

One of the main problems encountered is that modal parameter estimates are affected by different variables which are sometimes difficult to evaluate and control, such as environmental conditions, excitation techniques, data acquisition parameters, data processing methods and human factors. If the variation of the modal features due to these experimental parameters is of the same order than the variations due to damage, wrong conclusions could be drawn concerning the state of health of the structure.

The importance of the dynamic loading effect due to excitation devices is discussed in [6]. It is shown that the resonant frequencies shift with different 
excitation devices and the user has to be careful in the interpretation of the obtained results.

The recent wide diffusion of modal analysis identification techniques is due to some circumstances: even if the advent of modern computers, characterized by increasingly higher performance, allows the realization of complex models, dynamic properties, calculated with a finite element analysis, sometimes differ from the actual structure, as reported in many studies in scientific literature [7].

This difference is due to several causes:

- the finite element analysis is based on a discretization of reality;

- while mass and stiffness are easily assessable on the basis of material properties and geometry of the elements, is much more difficult to correctly reflect the damping properties of the structure within the model: structural damping is linked not only to material properties but also to a number of other effects, difficult to model (opening of micro-cracks in the concrete, interaction with non-structural elements, etc.);

- the actual geometry may be different from that considered in the model;

- mechanical properties of the materials may differ from those stated in the design phases, for a variety of causes involving environmental effects and casting operations [8].

To overcome all these difficulties, it is necessary to use experimental techniques in order to compare the model results with those obtained from on site measurements, thanks to the monitoring system; the collected data will enable to update the model in order to make it more consistent with reality.

In particular, with this aim, ambient vibration testing has become the main available experimental method to assess the dynamic behavior of full-scales structure since no excitation equipment is needed, and it involves a minimum interference with the normal use of the structure.

For the specific case presented, in addition to the environmental noise, the structure selected is prone to several induced vibrations due to excavation and dredging operations, which are currently taking place in the area surrounding the building (Figure 1).

The study presented focuses on the first stages of the project which now, however, is at a preliminary level. The monitoring system has been designed and it is expected to be installed and operating in a short time.

At this stage a large documentation has been collected in order to reconstruct the geometrical features and the history of the building, since it was originally made up of just one storey above ground and it has been recently involved in a raising intervention.

All this collected information has been the basis for the construction of a preliminary model; now it only consists of the central body but we expect to study the interaction between this part of the structure and the two stairwell bodies, joined on both sides of the building.

The final aim of this research is to develop a three-dimensional finite element model able to match the results of the experimental modal analysis; in order to 


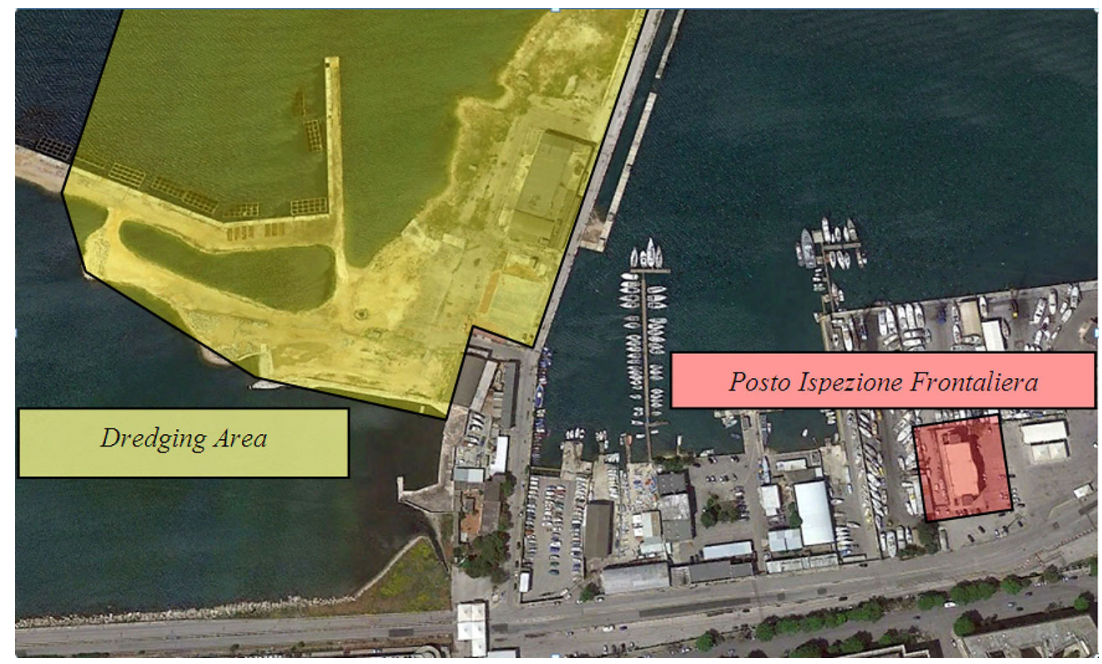

Figure 1: Site localization.

reach this purpose; some parameters have been selected as updating parameters; iteratively modifying them it will be possible to match the results of the experimental analysis and the finite element one. Some parameters have been already identified and concern with Young's modulus, the hypothesis of rigid or flexible diaphragms, and the effects of masonry infill.

\section{Experimental modal analysis}

Several studies in the civil engineering field concern with the theme of dynamic behavior of structures and it's possible to divide the approaches usually adopted to define it into two main groups:

- Analytical approach: knowing the geometry, load conditions, material properties, mass, stiffness and dumping distribution, it's possible to determine the modal parameters belonging to that structure, including natural frequencies and modal shapes

- Experimental approach: starting from a measurement of the dynamic input and the consequent structural response, functions describing this interaction can be calculated and, as a consequence, the dynamic parameters of the structure.

Experimental modal analysis (EMA) is also known as "inverse problem", opposite to the "direct problem" in which the input signal and the dynamic characteristics of the structure are known and the aim is to know the structural behavior [9].

In fact, with the experimental modal analysis, structural response and input signal are known and the structural features have to be determined. 
This analysis is based on the following assumptions:

- Linearity: the dynamic behavior of a structure is linear, so the response to a specific combination of input is in good agreement with the combination of outputs, that's to say the superposition principle is available.

- Lack of change: dynamic features of the structure don't change; as a consequence, coefficients in differential equations are constant

- Observability: all the essential data to determine the dynamic properties of interest should be measurable (here derives the need to place the measurement equipment in adequate locations).

These procedures help to identify the dynamic properties of the structure in terms of natural frequencies, damping ratios and modal shapes; the so determined parameters could be the basis to build a mathematical model of the dynamic behavior of the real structure.

The experimental modal analysis procedures, however, are based on a "known input": structures, in fact, are usually excited using one or more excitation sources; the response is measured in one or more points. Thus it is possible to identify modal parameters from frequency response function related to the input signal.

However, the input of the modal analysis could be unknown as well; environmental noise is the most common source in this kind of analysis.

In such cases the input is not known (in the sense that it cannot, in general, be measured) but modal analysis techniques can still be applied to evaluate the dynamic parameters of the structure; the different methods developed in this field use only the output data.

The modal analysis in the case of unknown input (the ambient noise for example) is called Operational Modal Analysis. OMA procedures, such as the classic EMA to assess natural frequencies, allow determining natural modes and damping ratios of the structure; however, it is not possible to calculate the modal participation factors, since the input isn't known.

For what concerns the specific case study, the input caused by excavation and dredging will be known since the main source of vibration can be localized and an estimate of the input acceleration is possible placing an acquisition accelerometer at the foundation level.

\section{Description of the case study}

The study presented focuses on a building in the Port area of Bari, in which the offices and the storage of the "Posto di Ispezione Frontaliero" (P.I.F.) are located.

It develops onto a gross area of 490 square meters and it was originally made up of only one storey above ground. The supporting structure, at the time of its construction, has been realized in order to allow the realization, later, of a second storey meant for offices. 
In 2003 a raising intervention was completed, and it led to the actual configuration of three stories above ground (Figures 2 and 3). All the structures, both foundation and elevation ones, are made of reinforced concrete.

Foundations consist of reverse crossed beams, while beams, columns and slabs compose elevated structures, both the existing and the newly realized ones. The two stairwell bodies, realized in reinforced concrete as well are joined to the main body.

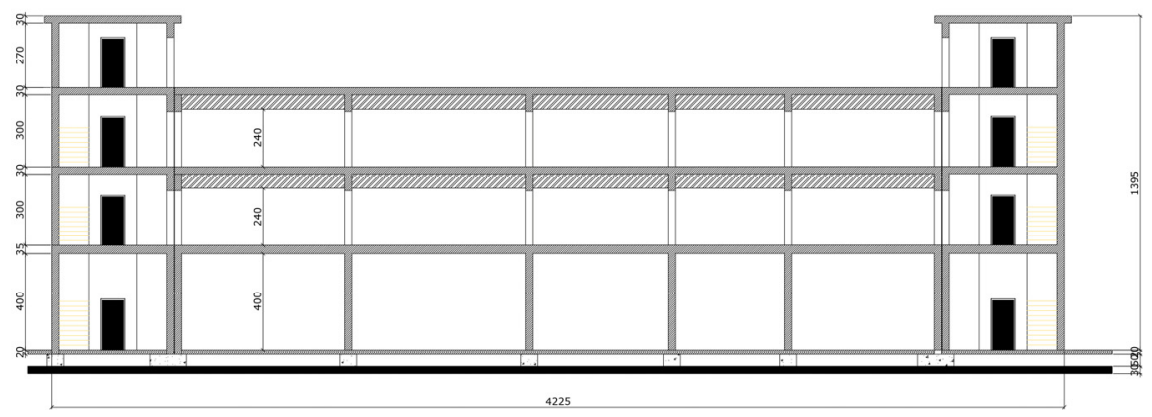

Figure 2: Section of the building.

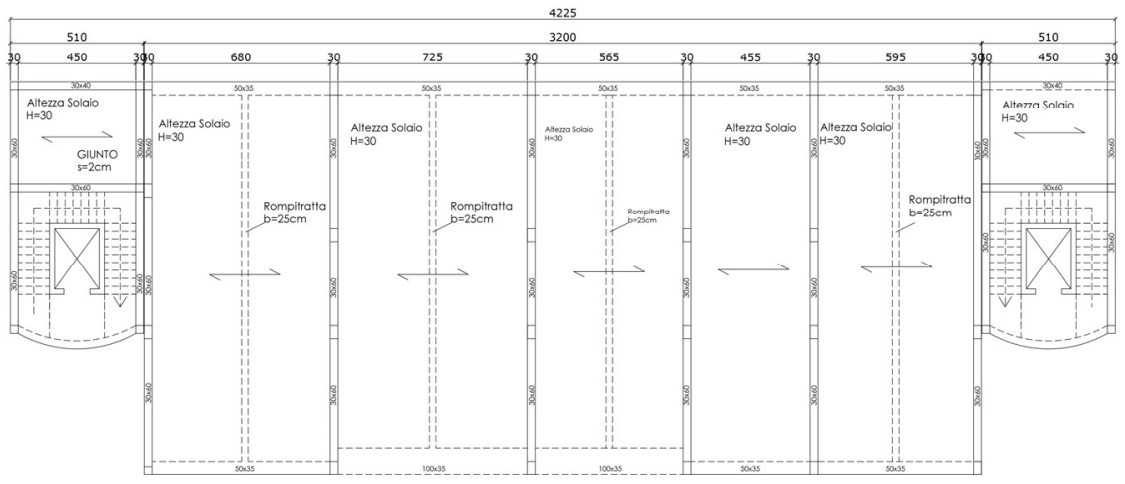

Figure 3: Structure plant.

Since the detection of the damage level induced in the structure and the assessment of an intervention plan for the adaption and seismic retrofitting are needed, in the same occasion, there will be the opportunity to collect, by a monitoring system directly installed in some relevant points of the structure, a series of in information which could also be used to update and optimize the numerical model.

The monitoring equipment needed consists of a total of 4 triaxial accelerometers, one to be placed at ground level and the other three to be located one on each floor. The system allows remote data acquisition and archiviation. 
A preliminary investigation on the basis of historical documents and on-site inspections allowed the identification of the structural geometry; then, a more accurate reconstruction of the geometric shape of the building has been made in order to proceed to the first stage of numerical modeling (finite element model, Figure 4) using the commercial software SAP2000.

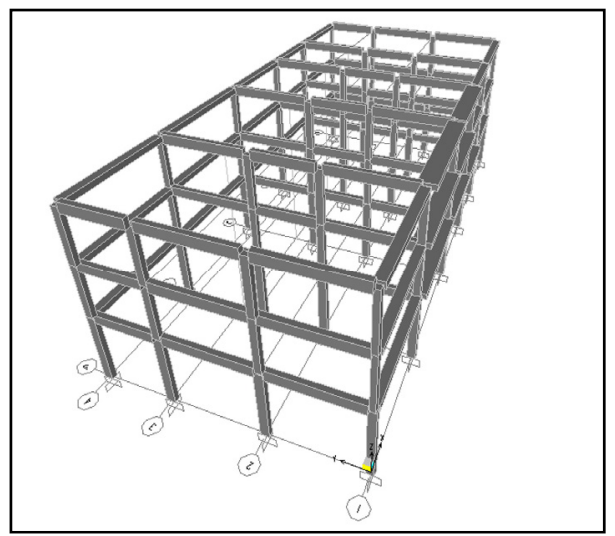

Figure 4: Fem model.

The investigation on the mechanical features of the materials, which at this stage is at a preparatory level, however, has been planned for the upcoming, more detailed, operations, on the basis of the numerous indications suggested in literature $[10,11]$.

The mechanical characterization of in situ materials is one of the most important issues in the safety assessment of existing buildings [12] and represents a major source of uncertainty.

The possibility of achieving a good "Level of Knowledge"' is strictly related to the availability of comprehensive experimental tests on the structures, including, if possible, destructive testing.

Both columns and beams will be investigated mostly with non-destructive tests, and an extensive database of results will be related to a small number of destructive tests.

\subsection{Some considerations about modeling}

Numerical characterization of the dynamic response of the structure has been made with a modal analysis using the software SAP2000. Implementation of the geometrical-structural model has been done in order to represent in detail the geometrical feature of the main body of the building (in this first phase the interaction with the two stairwell bodies has not been taken into account, though it will be a crucial element of the upcoming more precise modeling operations), keeping mechanical parameters within certain values, that would enable to carry out sensitivity analysis. 
One-dimensional elements (beams and columns) have been defined through frame-elements in the numerical model; bi-dimensional elements have been introduced to simulate the presence of decks; restraints between the structure and the ground are characterized by a complete lack of interaction.

The study of the dynamic features of the model has been carried out monitoring the variability of some parameters which may modify the response of the structure, such as the Young modulus (which varies within certain limit values), different configurations and behavior of the horizontal decks, given an unlimited stiffness or conversely a certain deformability.

The initial choice of these two parameters (stiffness of the material and assumption of rigid floor) is justified by the following considerations:

- Firstly, even permanent gravity loads could cause cracking, particularly for what concerns beams; therefore it is appropriate to assess the influence of the mechanical decay of the concrete

- Since there isn't any transversal connecting element between the main bending frames, it's likely that the assumption of rigid diaphrams (provided by Italian regulations) could play an important role in the definition of modal shapes, so the model has been analyzed also removing this hypothesis.

As said before, all structures are made of concrete, which, according to the documentation that has been previously collected, is thought to belong to a C12/15 class; that's to say with a compressive strength of $12 \mathrm{Mpa}$.

According to this, the Young's average modulus has been firstly determined according to Italian standards [13]:

$$
E_{c m}=22000\left(\frac{f_{c m}}{10}\right)^{0,3}=27085,2 \frac{\mathrm{N}}{\mathrm{mm}^{2}}
$$

At this stage of the study, the presence of the infill panels has been taken into account just for what concerns loadings on the bearing elements, though the participation of masonry infills to the overall seismic resistance of framed buildings has a significant role according to the specific mechanical characteristics of the infill, the geometrical distribution within the building and the local interaction among the panel and the surrounding primary RC elements. Especially in the case of structure designed only for vertical loads, essence of the infill can be decisive under an unexpected earthquake, providing an additional contribution to the strength and to the stiffness, as reported in numerous studies in literature [14-16].

Numerical analyses have therefore been made varying the Young modulus of the concrete: $100 \% \mathrm{Ecm}, 75 \% \mathrm{Ecm}, 50 \% \mathrm{Ecm}$; this variation has been combined with the rigid or flexible diaphragm hypothesis.

\section{First results}

In Figures 5 and 6, the first results of the numerical characterization of the model are summarized. 


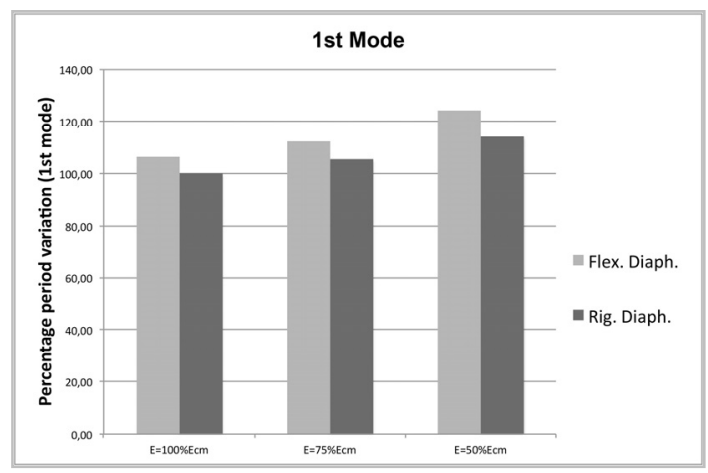

Figure 5: First mode.

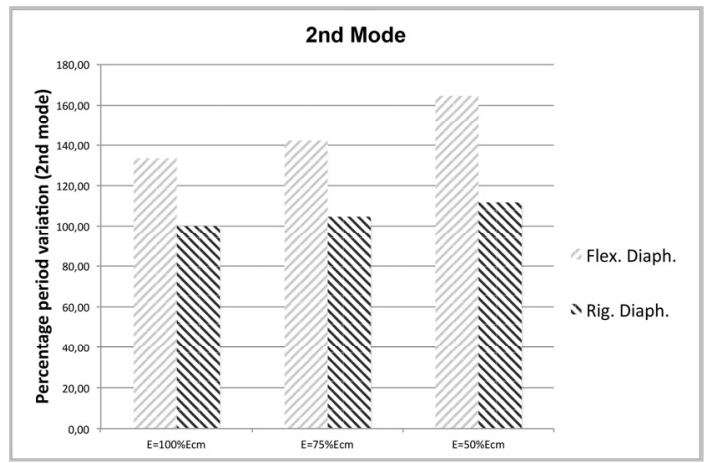

Figure 6: Second mode.

The results, summarized in the figures above, show how the calibration of the real Young's modulus for cracked concrete is the most relevant source of uncertainties (the percentage variation of the first mode vibration period is around $20 \%$, according to a variation of the modulus of elasticity from $100 \%$ to $50 \%$, while the percentage variation relative to the hypothesis of rigid or flexible diaphragm amounts to much lower values, on the order of $6 \%$ ); therefore, the rigid diaphragm hypothesis appears to affect less the response of the structure.

A reason could be found in the geometric features of the slab-floor: the thickness of $30 \mathrm{~cm}$ (and in certain areas $35 \mathrm{~cm}$ ) provides itself a relevant transverse stiffness to the structure.

On the basis of these numerical results and awaiting the start of field activities (further on-site investigation on the building, installation of the monitoring system) it's possible to assess the need to carry out a more detailed study at the elements' level to identify the areas that suffered, even under permanent actions, important cracking phenomena.

Once a good level of knowledge of the cracking state of structural elements will be reached, they could eventually be divided into "homogeneous groups", 
characterized by the same value of Young's modulus. A more accurate modeling of the structure will be therefore possible.

\subsection{Upcoming operations}

Experimental characterization of the dynamic parameters of the structure will be derived from the excitation caused by environmental noise and, above all, by dredging operations. The experimental results, collected through the monitoring campaign, will be compared with the numerical simulation results previously described.

Comparisons will concern with natural frequencies and mode shape vectors.

The dynamic-based assessment, involving both theoretical and experimental modal analysis, will include the following main steps:

1. Ambient vibration testing and, above all, measurement of vibrations caused by excavation.

2. Experimental modal analysis; the extraction of modal parameters (natural frequencies and mode shapes) from input-output experimental data comparisons.

3. Correlation of Finite element analysis (FEA) results with the experimental data.

4. Identification of the uncertain structural parameters of the model (model updating) by minimizing the difference between theoretical and experimental modal behavior.

\section{Expected results}

The vibration based investigation is thought to provide the following results:

- An estimate of the fundamental mode of the building, including frequency and dominant bending

- $\quad$ Other modes and main features

- Comparison between the different processing methods

- Comparison between measured and predicted modal parameters

- Evaluation of the influence of the selected updating parameters

In a final stage, on the basis of the result collected, once reached a good correspondence between the model and the measured parameters, it will be possible to predict the structural response of the structure to different load conditions.

\section{References}

[1] H.F. Lam, J.M. Ko, C.W. Wong, Localization of damaged structural connections based on experimental modal and sensitivity analysis. Journal of Sound and Vibration Volume 210, Issue 1, 12 February 1998, pp. 91115, doi: 10.1006/jsvi.1997.1302 
[2] J.M. Ndambi, B. Peeters, J. Maeck, J. De Visscher, M.A. Wahab, J. Vantomme, G. De Roeck, W.P. De Wilde, Comparison of techniques for modal analysis of concrete structures, Engineering Structures, Volume 22, Issue 9, September 2000, pp. 1159-1166, ISSN 0141-0296, doi: 10.1016/S0141-0296(99)00054-1.

[3] J. Maeck, M. Abdel Wahab, B. Peeters, G. De Roeck, J. De Visscher, W.P De Wilde, J.-M Ndambi, J Vantomme, Damage identification in reinforced concrete structures by dynamic stiffness determination, Engineering Structures, Volume 22, Issue 10, October 2000, pp. 13391349, ISSN 0141-0296.

[4] Clotaire Michel, Philippe Guéguen, Pierre-Yves Bard, Dynamic parameters of structures extracted from ambient vibration measurements: An aid for the seismic vulnerability assessment of existing buildings in moderate seismic hazard regions, Soil Dynamics and Earthquake Engineering, Volume 28, Issue 8, August 2008, pp. 593-604, ISSN 02677261, http://dx.doi.org/10.1016/j.soildyn.2007.10.002.

[5] Doebling S.W., Farrar C.F., Prime M.B., Shevitz D.W. Damage identification and health monitoring of structural and mechanical systems from changes in their vibration characteristics, a literature review. Research report LA-13070-MS, New Mexico: Los Alamos National Laboratory, 1996.

[6] Olbrechts T., Vandepite D., Sas P., Heylen W. Influence of excitation systems on the dynamic behaviour of test structures. In: Proc. of 21st Int. seminar on Modal Analysis (ISMA 21), Belgium, 1996: pp. 881-91.

[7] Hearn, G. and Testa, R. (1991) Modal Analysis for Damage Detection in Structures. Journal of Structural, October 1991, Vol. 117, No. 10: pp. 3042-3063, doi: 10.1061/(ASCE)0733-9445(1991)117:10(3042).

[8] Porco F., Uva G., Sangirardi M., Casolo S. (2013). About the reliability of punching verifications in reinforced concrete flat slabs. The Open Construction and Building Technology Journal, vol. 7, pp. 74-87, ISSN: 1874-8368, doi: 10.2174/1874836801307010074.

[9] Avitabile P., Experimental Modal Analysis: A Simple Non-Mathematical Presentation). S.V. Sound and Vibration, 2001, vol. 35, no. 1, pp. 20-31, ISSN 0038-1810.

[10] Fiore A., Porco F., Uva G., Mezzina M. (2013). On the dispersion of data collected by in situ diagnostic of the existing concrete. Construction and Building Materials, vol. 47, pp. 208-217, ISSN: 0950-0618, doi: 10.1016/j.conbuildmat.2013.05.001.

[11] Uva G., Porco F., Fiore A., Mezzina M. (2013). Proposal of a methodology for assessing the reliability of in situ concrete tests and improving the estimate of the compressive strength. Construction and Building Materials, vol. 38, pp. 72-83, ISSN: 0950-0618, doi: 10.1016/ j.conbuildmat.2012.08.025.

[12] Porco F, Porco G, Uva G, Sangirardi M. (2013). Experimental characterization of "non-engineered" masonry systems in a highly seismic 
prone area. Construction and Building Materials, vol. 48, pp. 406-416, ISSN: 0950-0618, doi: 10.1016/j.conbuildmat.2013.07.028.

[13] Ministero LL.PP. - Consiglio Superiore dei Lavori Pubblici, D.M. 14/01/2008 "Norme Tecniche per le Costruzioni”. Supplemento Ordinario no. 30 GazzettaUfficiale no. 29 del 4/02/2008.

[14] Fiore A, Porco F, Raffaele D, Uva G (2012). About the influence of the infill panels over the collapse mechanisms activated under pushover analyses: Two case studies. Soil Dynamics and Earthquake Engineering, vol. 39, pp. 11-22, ISSN: 0267-7261, doi: 10.1016/j.soildyn.2012.02.004.

[15] Uva G, Porco F, Fiore A (2012). Appraisal of masonry infill walls effect in the seismic response of RC framed buildings: A case study. Engineering Structures, vol. 34, pp. 514-526, ISSN: 0141-0296, doi: 10.1016/j.engstruct.2011.08.043.

[16] Uva G, Raffaele D, Porco F, Fiore A (2012). On the role of equivalent strut models in the seismic assessment of infilled RC buildings. Engineering Structures, vol. 42, pp. 83-94, ISSN: 0141-0296, doi: 10.1016/j.engstruct.2012.04.005. 